\title{
Effect of the Piston Crown Contour on the Fluid Flow of Diesel Engine using Biodiesel B30 Based on Simulation
}

\begin{abstract}
Semin $^{1}$, Beny Cahyono ${ }^{2}$, Taruno Ganggas D. B ${ }^{3}$
(Received: 22 August 2020 / Revised: 15 December 2020 / Accepted: 20 December 2020)

Abstract - diesel engines are categorized into internal combustion engines. On the internal combustion engine, combustion occurs in the combustion chamber. The combustion process requires three main elements: fuel, air, and heat from compression. The combustion process on the internal combustion engine will affect engine performance or emissions. The engine used is Yanmar TF85MH, one cylinder, four-stroke, direct-injection with B30 fuel palm oil. This study analyzes the effect of the piston bowl depth on the resulting fluid flow. To get the data, the author using the ANSYS software. The current piston bowl depth is $15,5 \mathrm{~mm}$. In this study, model variation with addition and reduction of $+2,+1,0,-1$, and -2 (in $\mathbf{m m}$ ). The results of the simulation show that the highest swirl ratio occurs in case 5 with a value of $-1,15$, the highest temperature occurs in case 4 with a value of $2373^{\circ} \mathrm{K}$, and the highest heat release rate occurs in case 4 with a value of $3,25 \times 10^{8}$ erg/degree.
\end{abstract}

Keywords - computational fluid dynamics, flow fluid, piston bowl.

\section{INTRODUCTION}

$\mathrm{T}$ he diesel engine is an internal combustion engine where combustion in a diesel engine occurs due to fuel injection, air supply, and heat due to compression in the combustion chamber [1]. Until now, diesel engines are still improving their performance and thermal efficiency. Besides, diesel engine exhaust emissions must also be adjusted to recognized standards. The emissions referred to are NOx and soot. NOx emissions occur as a result of the reaction of nitrogen and oxygen during the combustion process. NOx emissions can occur due to the inhomogeneity of the fuel and air mixture. The high temperature in the combustion chamber can also increase the NOx emission content [2].

There is a relationship between the entire exhaust gas with a mixture of fuel and air in the combustion process [3]. The combustion of fuel can be influenced by several factors, for example, injection pressure, piston shape, exhaust pattern, air rotation, the amount of fuel injected, etc. [4]. One journal [5] also claims that in the combustion process, the right mixture of air and fuel is needed. The airflow in the combustion chamber will also affect the combustion process in the diesel engine. There are two types of flow in the combustion chamber, namely, swirl and tumble [6]. Swirl flow is a flow of air that forms a loop or coil, while tumble flow is a flow of air that is perpendicular to the cylinder. In the

\footnotetext{
Semin, Department of Marine Engineering, Institut Teknologi. Sepuluh Nopember, Surabaya, 60111, Indonesia. E-mail: seminits@yahoo.com

Beny Cahyono, Department of Marine Engineering, Institut Teknologi. Sepuluh Nopember, Surabaya, 60111, Indonesia. E-mail: benyjtsp98@gmail.com

Taruno Ganggas D. B, Department of Marine Engineering, Institut Teknologi. Sepuluh Nopember, Surabaya, 60111, Indonesia. E-mail: tarunoganggas@gmail.com
}

combustion process, swirl flow is expected because it can increase the turbulent intensity [7,8]. The high turbulent intensity causes combustion in the combustion chamber to occur more thoroughly. Swirl flow can be obtained by changing the shape of the piston crown [9].

Several forms of piston crown have been analyzed, namely HCC (hemispherical combustion chamber), SCC (shallow depth combustion chamber), and TCC (toroidal combustion chamber). In his research, the piston with the shape of the TCC (toroidal combustion chamber) has the highest swirl ratio [1].

With this research, the most ideal geometry of the piston crown will be found so that there is no decrease in combustion quality when using B30 biodiesel fuel.

\section{METHOD}

\section{A. Research Problem}

At this stage, the authors formulate problems based on the implementation of biodiesel B30 in Indonesia. The use of biodiesel B30 can reduce engine performance. Therefore, we need a way to improve engine performance, one of which is by modifying the piston.

\section{B. Collecting Data}

In this research, several literature studies are needed in the simulation process. Likewise, the data required in this study are as follows:

\section{Piston Geometry}

In this study, the variation used is the depth of the piston bowl. However, to maintain the engine compression ratio, modification of the bowl piston diameter and TDC clearance is required. 


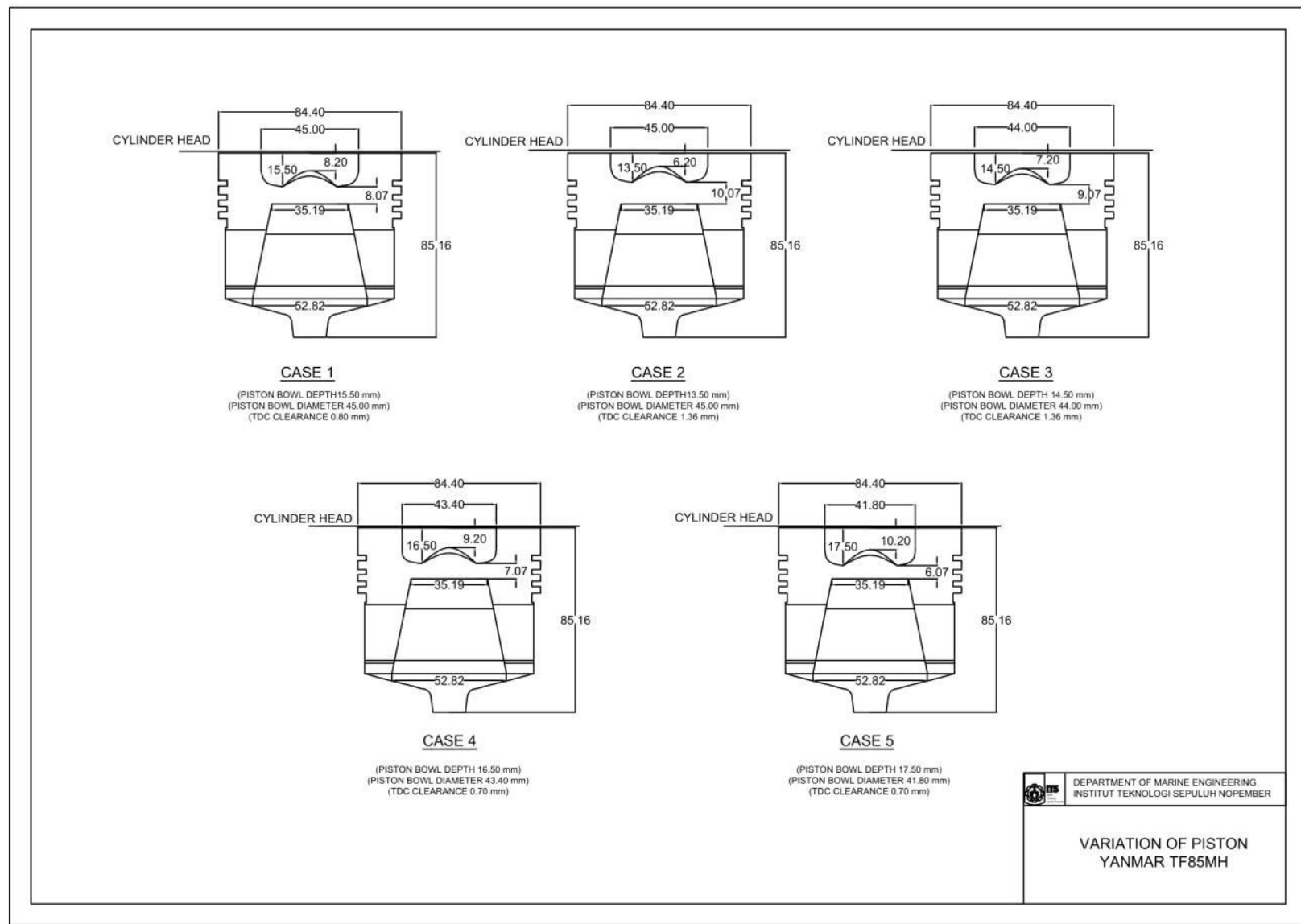

Figure. 1. Piston Variations

TABLE 1.

PISTON CROWN GEOMETRY

\begin{tabular}{cccc}
\hline CASE & Piston Bowl Depth & Piston Bowl Diameter & TDC Clearance \\
\hline Case 1 & $15,50 \mathrm{~mm}$ & $45,00 \mathrm{~mm}$ & $0,80 \mathrm{~mm}$ \\
Case 2 & $13,50 \mathrm{~mm}$ & $45,00 \mathrm{~mm}$ & $1,36 \mathrm{~mm}$ \\
Case 3 & $14,50 \mathrm{~mm}$ & $44,00 \mathrm{~mm}$ & $1,36 \mathrm{~mm}$ \\
Case 4 & $16,50 \mathrm{~mm}$ & $43,40 \mathrm{~mm}$ & $0,70 \mathrm{~mm}$ \\
Case 5 & $17,50 \mathrm{~mm}$ & $41,80 \mathrm{~mm}$ & $0,70 \mathrm{~mm}$ \\
\hline
\end{tabular}

2. Engine Specification

TF85MH manual.

Engine specifications are obtained from the Yanmar

TABLE 2.

YANMAR TF85MH SPECIFICATION

\begin{tabular}{lll}
\hline 1 & Number of cylinders & One Cylinder \\
2 & Injection timing & 18 before TDC \\
3 & Bore x Stroke & $85 \mathrm{~mm} \times 87 \mathrm{~mm}$ \\
4 & Volume of cylinder & $493 \mathrm{cc}$ \\
5 & Compression ratio & 18
\end{tabular}

$70 \%$ HSD fuel and 30\% Methyl Palmitate or Fatty Acid Methyl Ester (FAME).

3. Fuel Characteristics

As data input in the ANSYS software, the fuel composition to be used is required, namely palm oil biodiesel B30. The composition of B30 biodiesel is

\section{Air Composition}

TABLE 3.

AIR COMPOSITION

\begin{tabular}{cc}
\multicolumn{2}{c}{ AIR COMPOSITION } \\
\hline $\mathrm{O}_{2}$ & $13,69 \%$ \\
$\mathrm{~N}_{2}$ & $74,73 \%$ \\
$\mathrm{CO}_{2}$ & $7,89 \%$ \\
$\mathrm{H}_{2} \mathrm{O}$ & $3,69 \%$ \\
\hline
\end{tabular}




\section{CFD Modelling}

After determining the geometry modeling of the piston bowl, it is necessary to manufacture the main components in the combustion chamber (cylinder head, cylinder liner, and piston) in 3D with dimensions as shown above. The software used by the writer in modeling is SOLIDWORKS. Then these components need to be carried out by the assembly process at SOLIDWORKS and continued by making a negative volume of the combustion chamber with each predetermined piston model. To be simulated using Ansys Forte, it is necessary to convert the data to Parasolid (*. X_t).

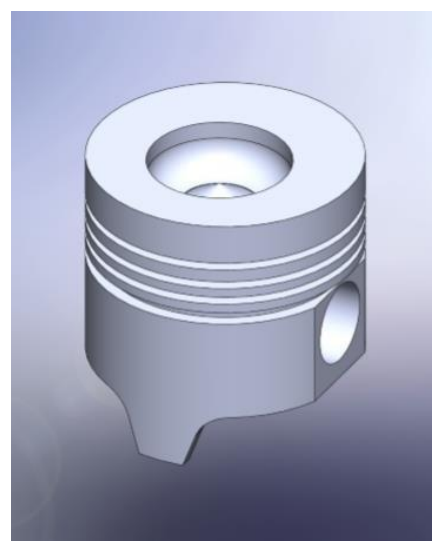

Figure.2. Isometric View Piston Standard 3D

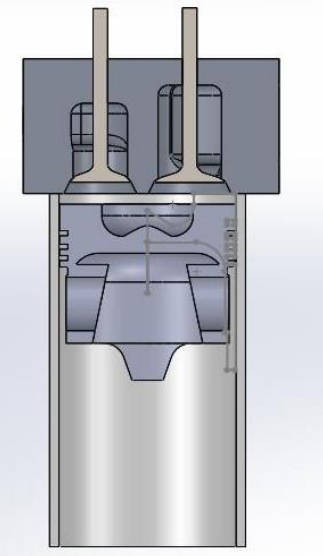

Figure. 3. Front View Combustion Chamber 3D

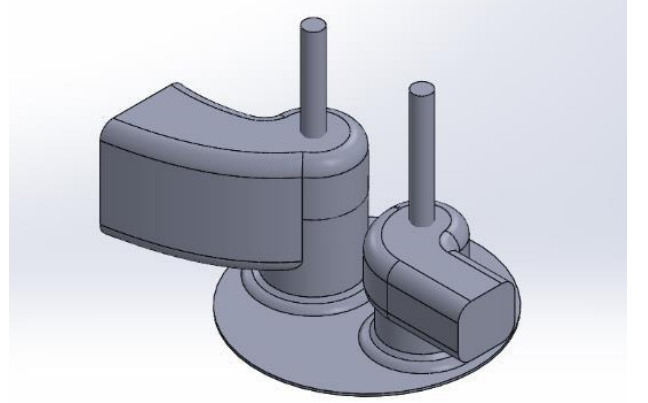

Figure. 4. Flow Domain Yanmar TF85MH in Parasolid $\left(* . x \_t\right)$

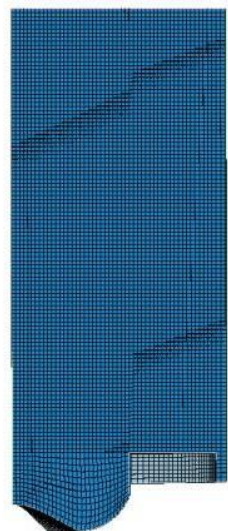

Figure. 5. Meshing on Forte Mesh Generator 


\section{CFD Simulation}

This simulation uses ANSYS ICE FORTE software using the Yanmar TF85MH engine with a variety of piston models and uses palm oil B30 biodiesel as a fuel. At this stage, some data has been required that need to be input, such as the spray model, initial conditions, and boundary conditions. The data used can be seen in the following table:

TABLE 4.

SPRAY MODELS

\begin{tabular}{cc}
\multicolumn{2}{c}{ SPRAY MODELS } \\
\hline Inflow droplet temperature & $305^{\circ} \mathrm{K}$ \\
Mean cone angle & $11^{\circ}$ \\
Nozzle diameter & $0,025 \mathrm{~cm}$ \\
Start of injection & $18{ }^{\circ} \mathrm{CA} \mathrm{BTDC}$ \\
Duration of injection & $36^{\circ}$ \\
Total injected mass & $22 \mathrm{mg}$ \\
\hline \multicolumn{2}{c}{ TABLE 5. } \\
BoundARY CONDITIONS \\
\hline Piston temperature & $500{ }^{\circ} \mathrm{K}$ \\
Cyl. head temperature & $500^{\circ} \mathrm{K}$ \\
Cyl. Liner temperature & $430{ }^{\circ} \mathrm{K}$ \\
\hline
\end{tabular}

TABLE 6.

\begin{tabular}{lc}
\multicolumn{2}{c}{ INITIAL CONDITIONS ON $60^{\circ} \mathrm{BTDC}$} \\
\hline Temperature & $500{ }^{\circ} \mathrm{K}$ \\
Pressure & $7,55 \mathrm{bar}$ \\
\hline
\end{tabular}

\section{A. Output Simulation}

After the CFD simulation using ANSYS ICE Forte software is complete, several outputs are obtained that will answer the research objectives. From the simulation results, a graph of the swirl ratio, maximum temperature, and heat release rate will be obtained using several variations in the depth of the piston bowl. In addition, image visualization of the velocity of fluid and temperature in the combustion chamber is also obtained.

\section{B. Discussion and Conclusion}

When all the necessary data have been collected, it is followed by an analysis that will answer all the research objectives set by the author. Analysis can be carried out when all the necessary data have been collected. The results of the analysis must answer all of the research objectives set by the author.

\section{RESULTS AND DISCUSSION}

\section{A. Swirl ratio}

Based on the iteration results obtained from the simulation, case 1 produces a swirl ratio of -1.105 at $3^{\circ}$ crank angle before TDC, case 2 produces a swirl ratio of -0.98 at $5^{\circ}$ crank angle before TDC, case 3 produces a swirl ratio value of -0.99 at 4.94 crank angle before TDC, case 4 produces a swirl ratio value of -1.13 at $4^{\circ}$ crank angle before TDC, while case 5 produces the highest swirl ratio value of -1.15 at $4,5^{\circ}$ crank angle before TDC. 


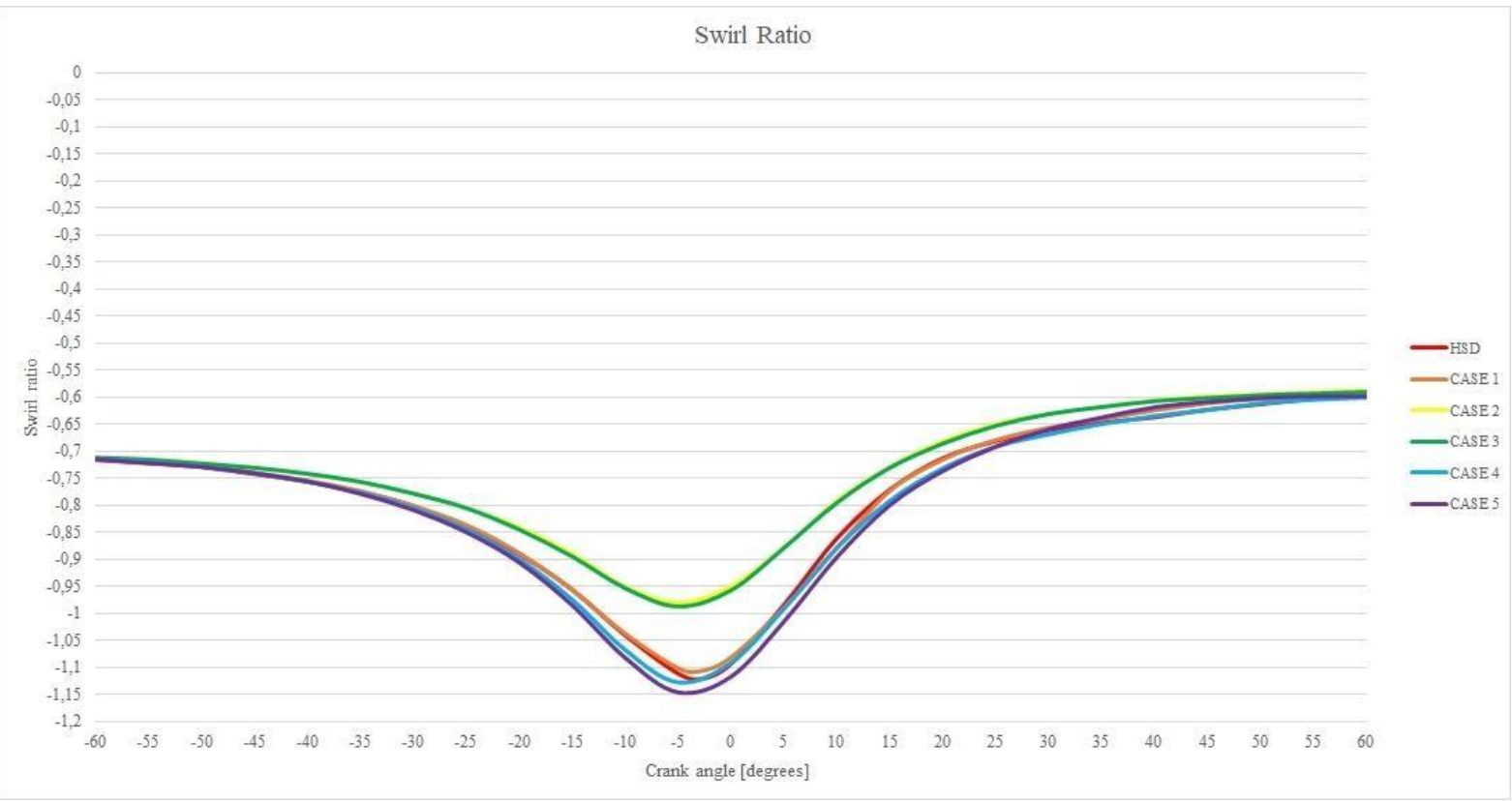

Figure. 6.Swirl Ratio

However, when the TDC position, case 1 has a swirl ratio value of -1.08 , case 2 has the lowest swirl ratio value of -0.95 , case 3 has a swirl ratio value of -0.958 , case 4 has a swirl ratio value of $-1,092$, and case 5 has a swirl ratio of $-1,117$. From the simulation results, it can be seen that the swirl ratio in case 2 and case 3 has decreased. Whereas in case 4 and case 5 it is bigger than the normal piston fueled by biodiesel B30 (case 1).
From these results, it can be seen that changes in the geometry of the piston bowl with a reduction in the depth of the piston bowl and the addition of TDC clearance affect the decrease in the swirl ratio. Meanwhile, changing the piston model by increasing the depth of the piston bowl along with a reduction in the TDC clearance can increase the swirl ratio value.

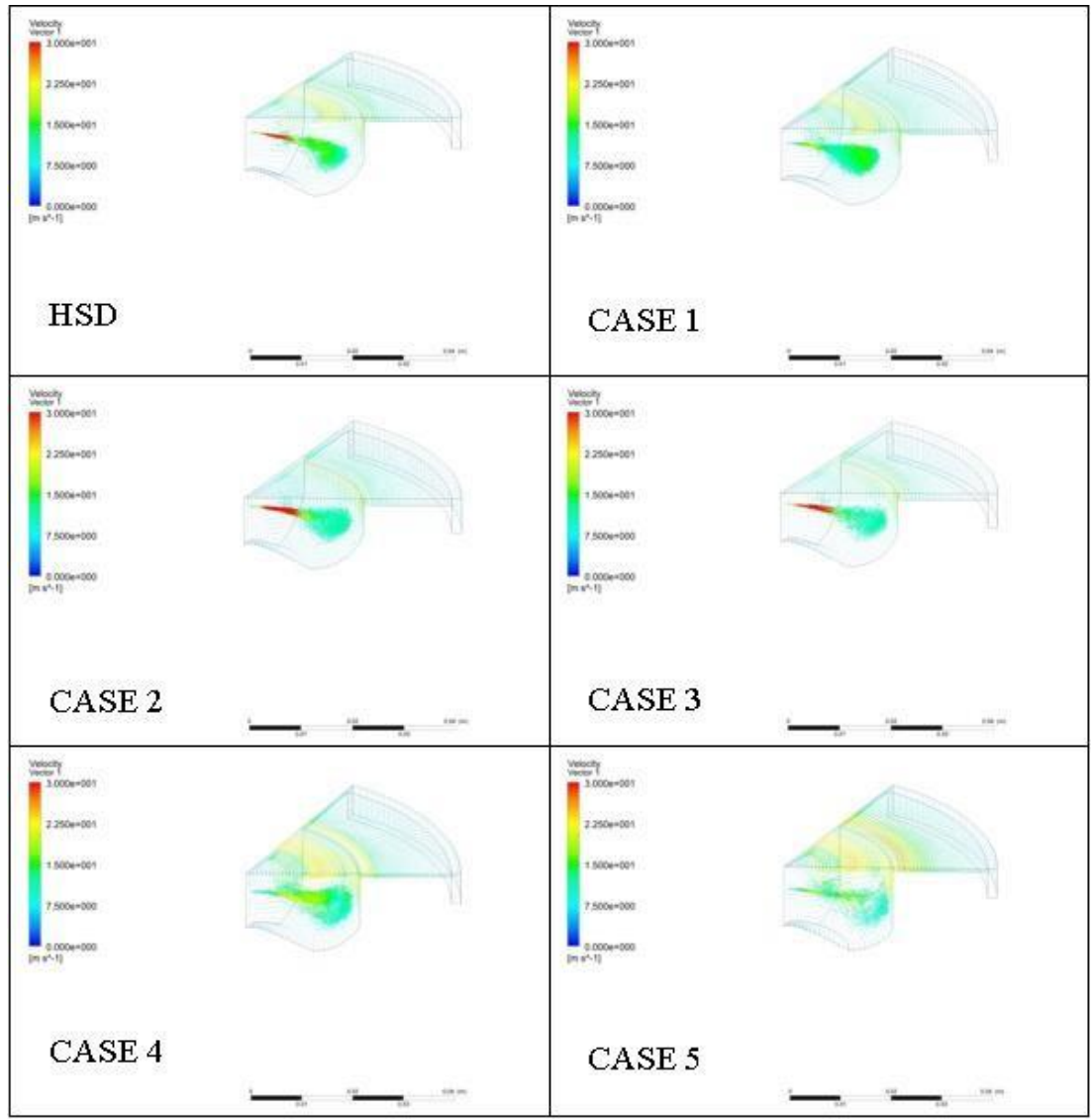

Figure. 7. Velocity of Fluid at TDC 


\section{B. Velocity}

Figure 7 is a visualization of the velocity of the fluid in the combustion chamber at TDC. From the velocity of fluid visualization, it can be seen that the faster the airflow, the redder the color will be seen on the velocity vector. It can be seen in the figure that changing the geometry of the piston crown can change the shape of the fuel injection from the injector. From the picture above, it can be seen that the reduction in the depth of the piston bowl and the addition of TDC clearance (in case 2 and case 3 ) indicates that the fuel distribution is not good, whereas with the addition of the piston bowl depth and the reduction in TDC clearance (in case 4 and case 5) may cause more diffuse injection of fuel through the injector. This is due to the change in the swirl ratio that affects the spread of fuel injection.

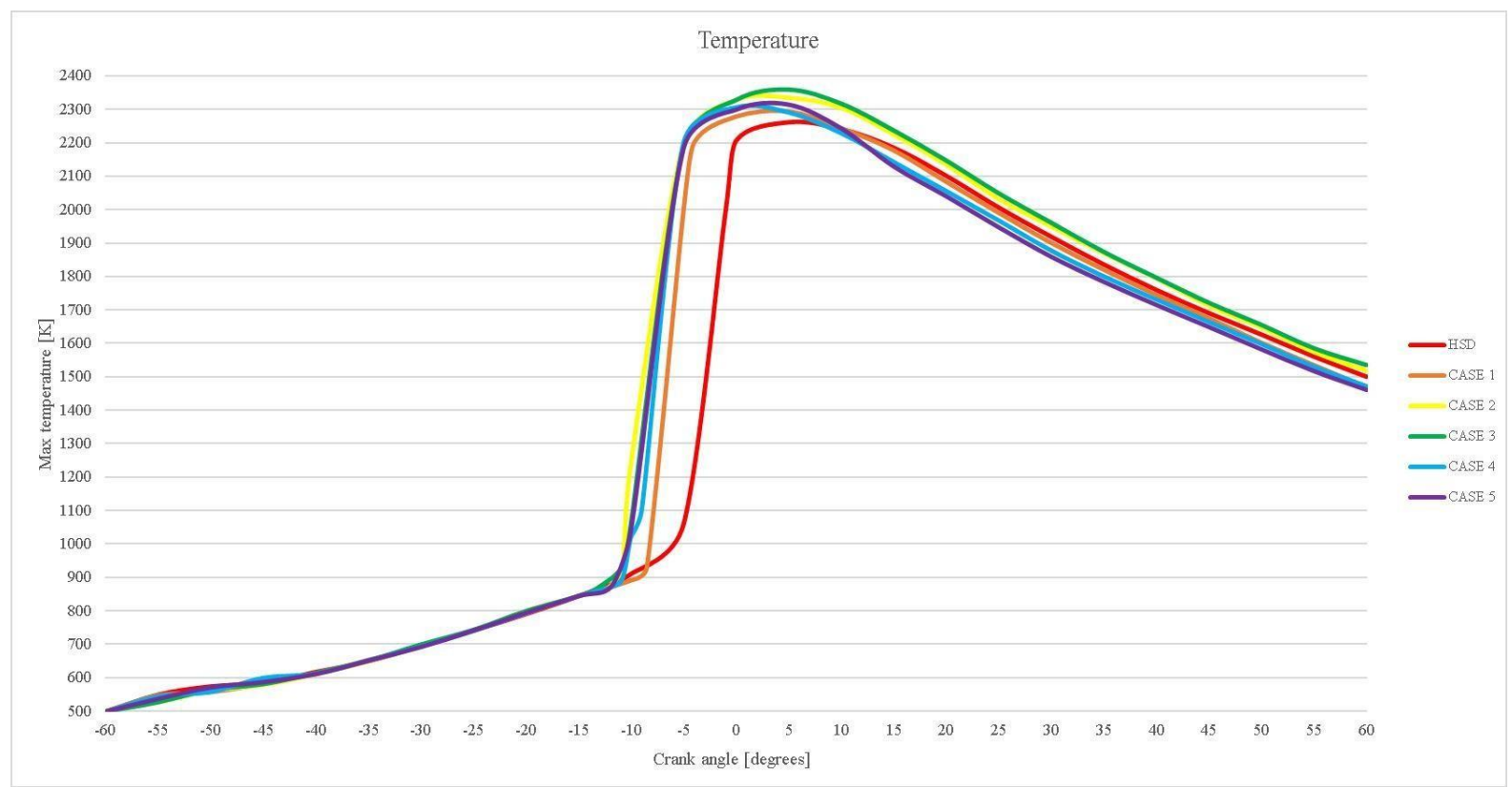

Figure. 8. Temperature

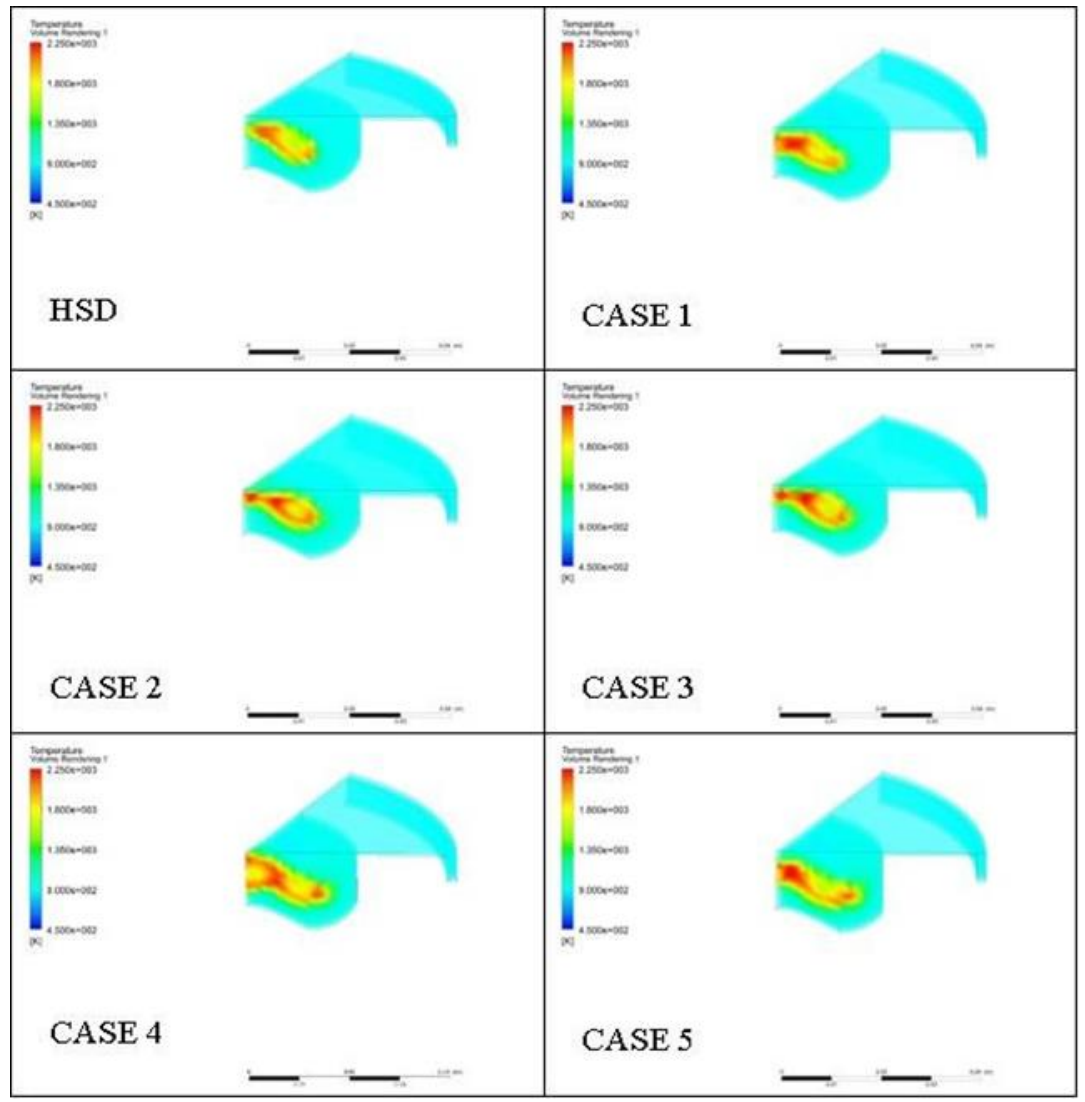

Figure. 9. Temperature Distribution at TDC 
International Journal of Marine Engineering Innovation and Research, Vol. 5(4), Dec. 2020. 274-282 (pISSN: 2541-5972, eISSN: 2548-1479)

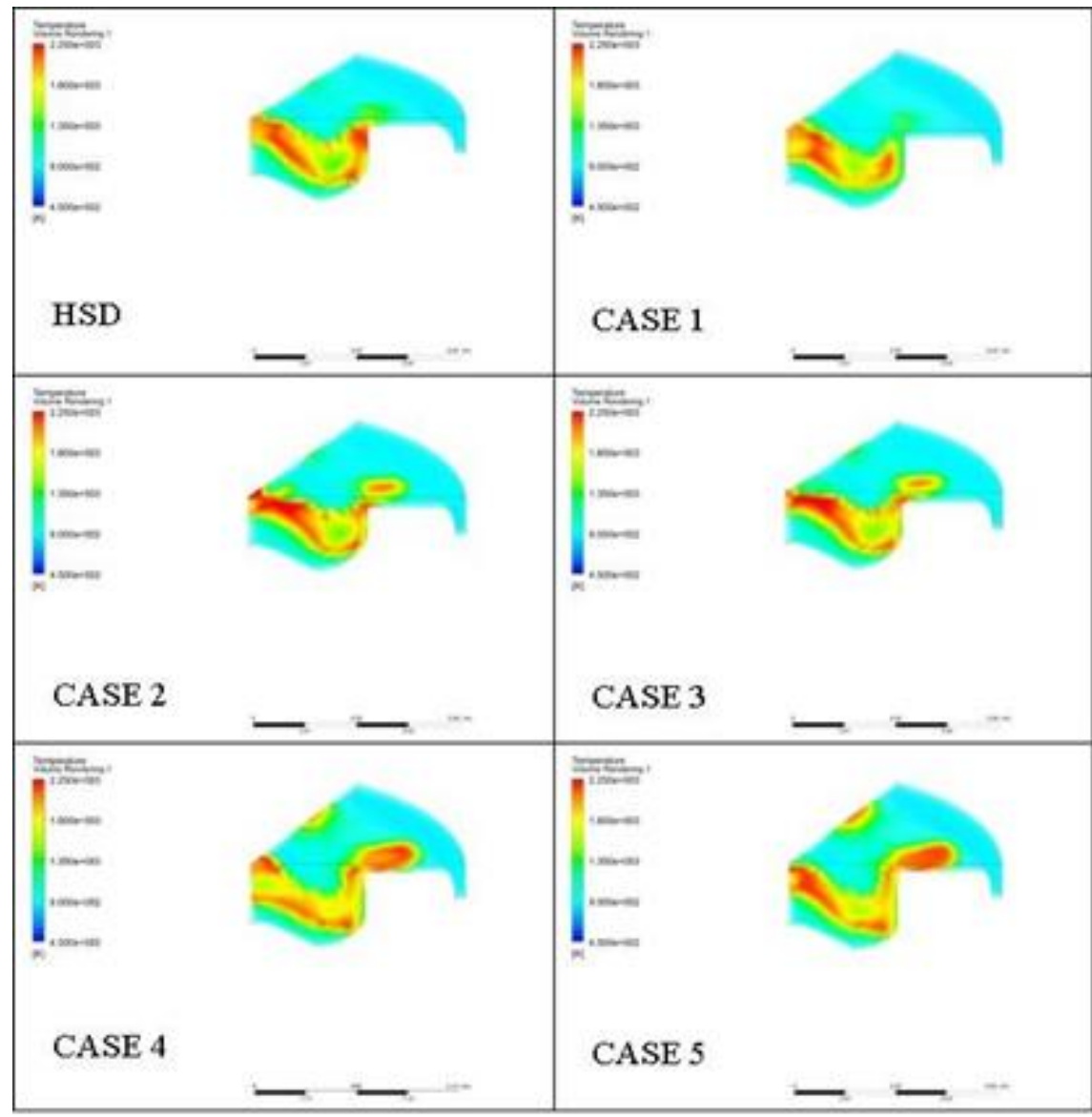

Figure. 10. Temperature Distribution at TDC

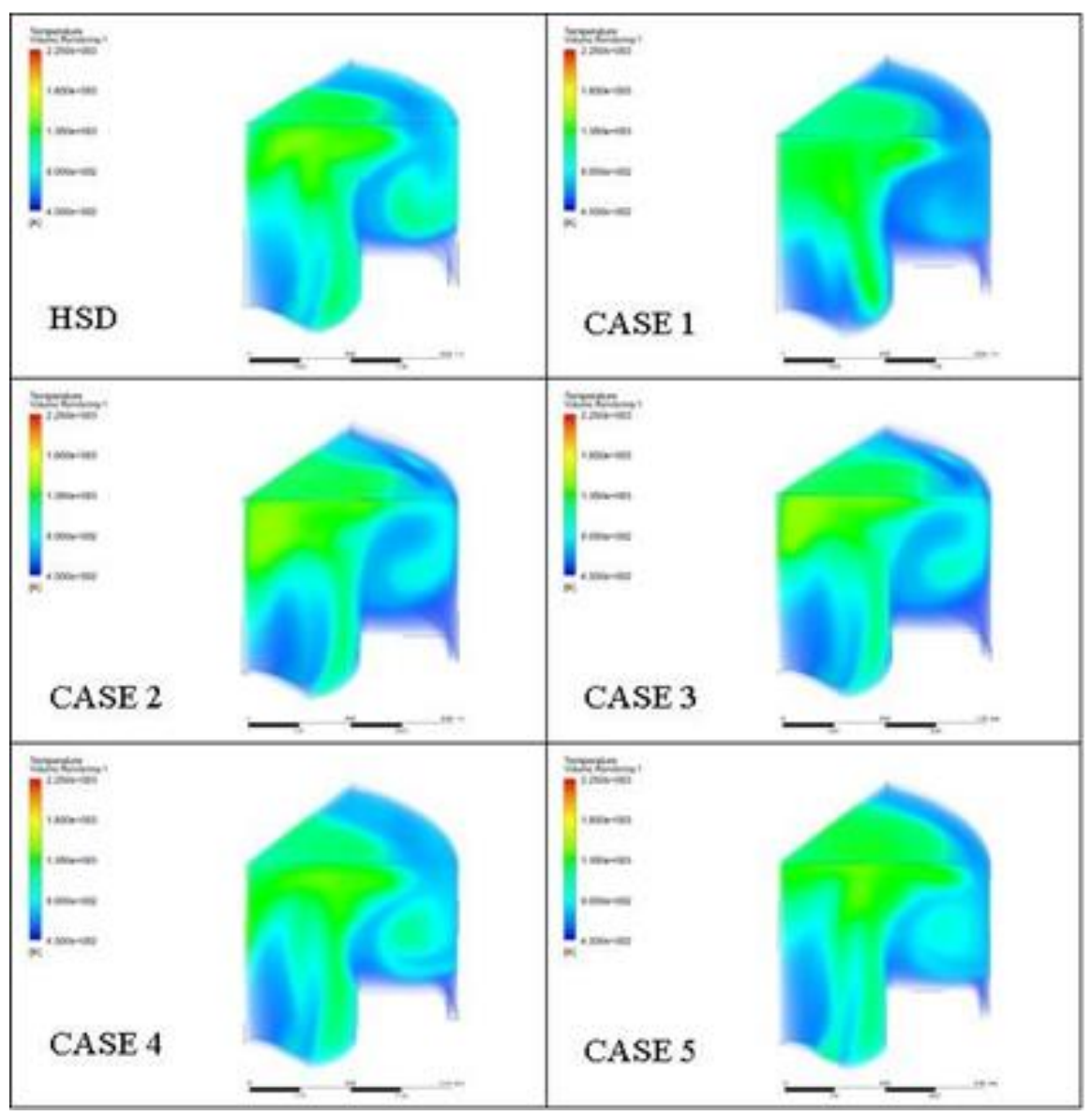

Figure. 11. Temperature Distribution on $60^{\circ} \mathrm{CA}$ ATDC 


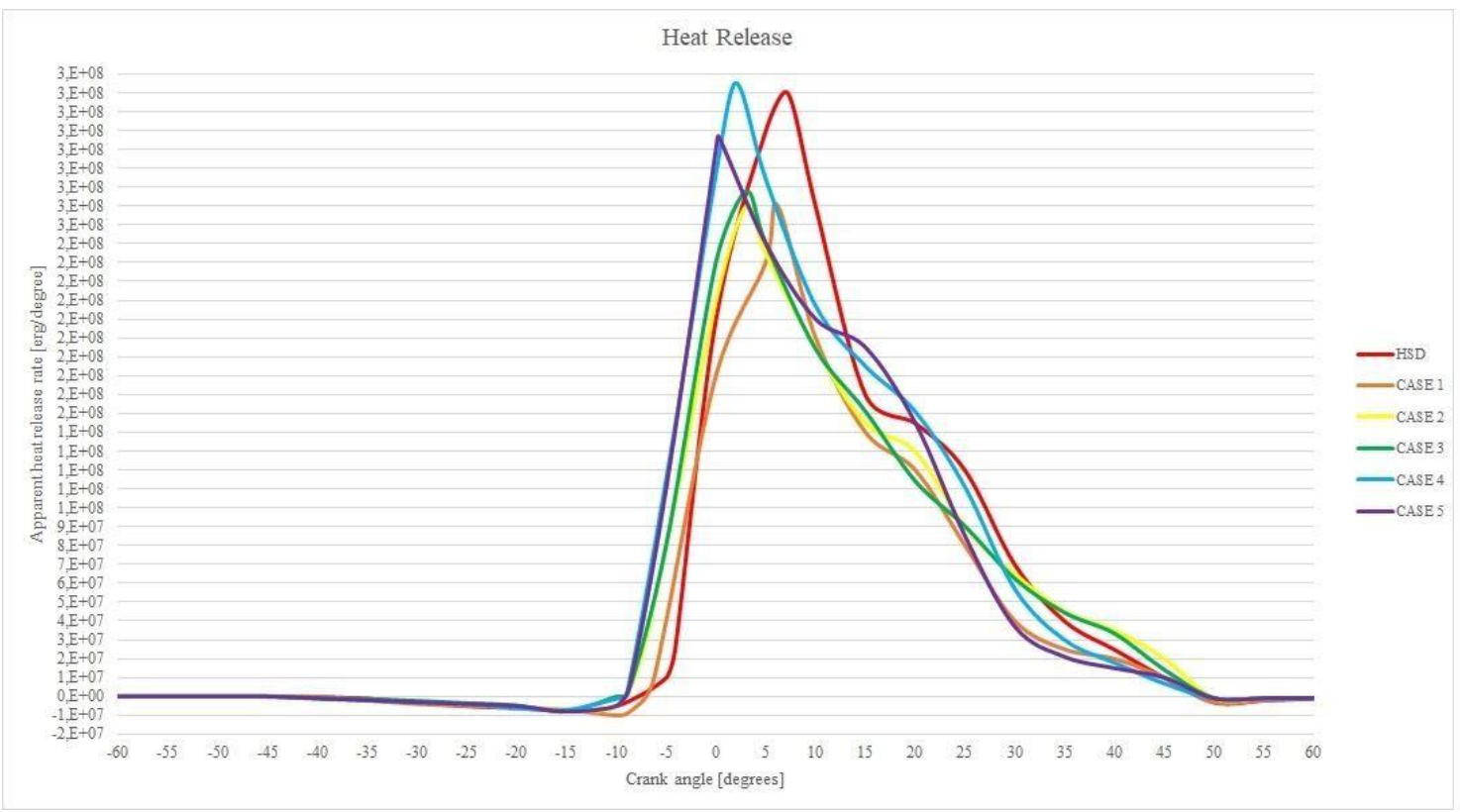

Figure. 12. Heat Release Rate

\section{Temperature}

Figure 8 is a temperature graph with a variety of models. From the results of the iteration, case 1 produces a maximum temperature of $2290{ }^{\circ} \mathrm{K}$ at $5^{\circ}$ crank angle after TDC, case 2 produces a maximum temperature of $2345^{\circ} \mathrm{K}$ at $4.11^{\circ}$ crank angle after TDC, case 3 produces a maximum temperature of $2357^{\circ} \mathrm{K}$ at $4.04^{\circ}$ crank angle after TDC, case 4 produces the highest maximum temperature of $2373{ }^{\circ} \mathrm{K}$ at $5^{\circ}$ crank angle after TDC, and case 5 produces a maximum temperature of $2318^{\circ} \mathrm{K}$ at $5^{\circ}$ crank angle after TDC.

However, when the TDC position, as in the table, case 1 has a maximum temperature of $2270{ }^{\circ} \mathrm{K}$, case 2 has the highest maximum temperature of $2328^{\circ} \mathrm{K}$, case 3 has a maximum temperature of $2322^{\circ} \mathrm{K}$, case 4 has a maximum temperature of $2305{ }^{\circ} \mathrm{K}$, and case 5 has a maximum temperature of $2290{ }^{\circ} \mathrm{K}$. This is due to differences in the fuel ignition period.

From the simulation results, the normal piston ignition process using HSD fuel starts from $5^{\circ}$ crank angle before TDC, whereas if using biodiesel fuel B30 (case 1) starts from $9^{\circ}$ crank angle before TDC, case 2 starts from $10^{\circ}$ crank angle. Before TDC, case 3 started at $11^{\circ}$ crank angle before TDC, case 4 started at $12^{\circ}$ crank angle before TDC, case 5 started at $12^{\circ}$ crank angle before TDC. From these results, it can be concluded that the fuel can affect the ignition delay. Ignition delay in case 1 with HSD fuel is longer when compared to biodiesel fuel B30.

With this simulation, visualization of temperature distribution is obtained which is taken from $-60^{\circ}$ crank angle before TDC to $60^{\circ}$ crank angle after TDC.

Figure 9 is a visualization of the temperature in the combustion chamber at TDC. It can be seen in the picture above that HSD fuel is more difficult to burn than biodiesel fuel B30. The high temperature is caused by the ignition process as a result of injecting fuel into the combustion chamber.
Figure 10 is a visualization of the temperature in the combustion chamber at a $10^{\circ}$ crank angle after TDC. At this position, the temperature distribution on the HSD case and case 1 is getting closer to the cylinder head. Meanwhile, the spread of heat from case 2 and case 3 has flowed between the top piston and cylinder head towards the cylinder liner, while the temperature distribution in case 4 and case 5 is more spread out compared to other types of pistons.

\section{Heat Release Rate}

Based on the iteration results obtained from the case 1 simulation results in a heat release rate of $2,6 \times 10^{8}$ erg/degree at $6,2^{\circ}$ crank angle after TDC, case 2 results in a heat release rate of $2,64 \times 10^{8} \mathrm{erg} /$ degree at $3,02^{\circ}$ crank angle after TDC, case 3 produces a heat release rate value of $2,67 \times 10^{8} \mathrm{erg} /$ degree at $3,15^{\circ}$ crank angle after TDC, case 4 produces a heat release rate of $3,2 \times 10^{8}$ erg/degree at $2^{\circ}$ crank angle after TDC, while case 5 produced the highest heat release rate value of $2,97 \times 10^{8}$ erg/degree at $0,175^{\circ}$ crank angle after TDC.

But when the TDC position, case 1 has a heat release rate value of $1,7 \times 10^{8} \mathrm{erg} /$ degree, case 2 has the lowest heat release rate value of $2,35 \times 10^{8} \mathrm{erg} / \mathrm{degree}$, case 3 has a heat release rate value of $2,3 \times 10^{8} \mathrm{erg} /$ degree, case 4 has a heat release rate value of $2,77 \times 10^{8} \mathrm{erg} /$ degree, and case 5 has a heat release rate value of $2,8 \times 10^{8} \mathrm{erg} /$ degree.

As seen in the graph, the trend of the ignition process when using B30 biodiesel fuel is faster than using HSD fuel. If a normal piston uses Biodiesel B30 fuel, the maximum heat release rate value decreases by $6 \times 10^{7}$ erg/degree which results in the smallest heat release rate value occurring in case 1 .

However, with the modification process in the piston bowl, the heat release rate can be increased. As in the graph, case 4 has a heat release rate of $3,25 \times 10^{8}$ erg/degree at a $2^{\circ}$ crank angle after TDC. 


\section{CONCLUSION}

The conclusions that can be drawn from this research are as follows:

1. Different contours of piston crowns with the same compression ratio can affect the swirl ratio changes. With the reduction of the piston bowl depth and the addition of TDC clearance, it can reduce the swirl ratio. On the other hand, the increase of the piston bowl depth and reduce the TDC clearance, can increase the swirl ratio. The highest swirl ratio is seen in Case 5 with a maximum value of $-1,15$ at $4.5^{\circ}$ crank angle before TDC. Changes in the swirl ratio value can also affect the spread of fuel injection.

2. Different contours of piston crown with the same compression ratio can affect the temperature distribution in the combustion chamber. The highest temperature distribution can be seen in Case 4 with a maximum temperature value of $2373 \mathrm{~K}$ at $5^{\circ}$ crank angle after TDC.

3. Changing the fuel from HSD to Biodiesel B30 can reduce the heat release rate of the engine with a decrease of $6 \times 10^{7} \mathrm{erg} /$ degree. With the modification of the piston bowl, it can be concluded that Case 4 has the highest heat release rate of $3,25 \times 10^{8}$ erg/degree at a $2^{\circ}$ crank angle after TDC.

\section{REFERENCES}

[1] Semin,2008. Investigation of Diesel Engine Performance Based on Simulation. American Journal of Applied Sciences 5 (6): 610-617, 2008 ISSN 1546-9239

[2] Prabhakara Rao Ganji, 2018. Design of piston bowl geometry for better combustion in direct-injection compression ignition engine. Department of Mechanical Engineering, National Institute of Technology, Warangal 506 004, India.

[3] Li J, Yang W M, An H, Maghbouli A, Chou S K, 2014. Effects of piston bowl geometry on combustion and emission characteristics of biodiesel fueled diesel engines. Li J, Yang $W M$, An $H$, Maghbouli A and Chou S K 2014 Effects of piston bowl geometry on combustion and emission characteristics of biodiesel fueled diesel engines. Fuel 120;66-73.

[4] Annamalai R., 2017. Effect of Piston Bowl Geometry and Different Injection Pressure on The Performance, Emission, and Combustion Characteristics of Diesel Engine Using Biodiese Blend. Department of Mechanical Engineering, Dr.M.G.R Educational and Research Institute, University, Chennai-600095, India.

[5] Lim J, Min K, 2005. The effects of spray angle and piston bowl shape in diesel engine soot emission during 3-D CFD simulation. Lim J and Min K 2005 The effects of spray angle and piston bowl shape in diesel engine soot emission during 3-D CFD simulation (No. 2005-01-2117). In: SAE Technical Paper.

[6] Semin, 2018. Analysis of Influence of Masks Flow on Intake Valve of Gas and Oil Fuel Engine Based Simulation. International Journal of Marine Engineering Innovation and Research.

[7] Semin, 2018. Technical Review of Fin Addition Analysis of Air Intake Valve on Gas-Oil Fuel Engine. International Journal of Marine Engineering Innovation and Research.

[8] Semin,2019. Intake Valve Lift Effect on Air-Fuel Mixing of Dual Fuel Engine. International Journal of Mechanical Engineering and Technology (IJMET)

[9] Glenn Cahya D.R., 2013. Kajian Aliran Fluida pada Mesin Otto Empat Langkah. Kajian aliran fluida pada mesin otto empat langkah, Glenn Cahya Dwi Ramadhan, FT UI, 2013

[10] Daryanto, Setyabudi. I, 2013. Teknik Motor Diesel. 2nd ed. Bandung: Alfabeta.

[11] Gosh, A., 2016. Combustion Chambers In CI Engines : A Review. Proceedings of National Conf. on Recent Innovations in Science Engineering \& Technology, 31st January 2016, Pune, India, ISBN: 978-93-85973-22-2.

[12] Ilker Sugozu, T. E. I. O. O. S., 2011. Biodiesel production from animal fat-palm oil blend and performance analysis of its effects on a single cylinder diesel engine. Energy Education Science and Technology Part A: Energy Science and Research 2011 Volume (issues) 28(1): 505-514.

[13] Ilker Temizer, O. C. B. E., 2020. Numerical and experimental investigation of the effect of biodiesel/diesel fuel on combustion characteristics in CI engine. Fuel 270 (2020) 117523.

[14] P. Prabhkaran, C. G. S. R. V. M. V. N. M. K. A., 2020. Investigation of swirl induced piston on the engine characteristics of a biodiesel fueled diesel engine. Fuel 279 (2020) 118503.

[15] Beny Cahyono, A. I. A. R., 2020. Optimization of Cold EGR (Exhaust Gas Recirculation) on Diesel Motors Using Biodiesel on The Performance. International Journal of Marine Engineering Innovation and Research. 